\title{
Serially expanded flap use to treat large hairless scalp lesions
}

\author{
Dongwoo Shin ${ }^{1}$, \\ Yong Hun $\mathrm{Kim}^{2}$, \\ Han Gyeol Song ${ }^{3}$, \\ Jong Won Hong ${ }^{1}$ \\ ${ }^{1}$ Department of Plastic and \\ Reconstructive Surgery, Institute for \\ Human Tissue Restoration, Yonsei \\ University College of Medicine, Seoul; \\ ${ }^{2}$ Department of Plastic and \\ Reconstructive Surgery, Wonju \\ Severance Christian Hospital, Yonsei \\ University Wonju College of Medicine, \\ Wonju; ${ }^{3}$ Kodi Medical Group, Seoul, \\ Korea
}

\begin{abstract}
Hairless scalp areas can occur due to trauma, tumors, or congenital disease. This aesthetically unpleasing condition can lead to psychosocial distress, and thin skin flaps may be prone to scarring. Treating the hairless scalp by simple excision is challenging because of skin tension. Tissue expanders are a good option for hairless scalp resurfacing. However, a single expansion may be inadequate to cover the entire defect. This report describes good results obtained using a serial resurfacing method involving re-expansion of the flap with a tissue expander to treat two patients with large lesions: one due to aplasia cutis congenital and another who underwent dermatofibrosarcoma protuberance resection. The results suggest that scalp resurfacing by serial tissue expansion using a tissue expander can be used for extensive lesions.
\end{abstract}

Keywords: Alopecia / Scalp / Tissue expansion

\section{INTRODUCTION}

Extensive scalp reconstruction is a challenging procedure for plastic surgeons. Hairless scalp can occur due to congenital diseases like aplasia cutis congenita (ACC) or trauma or surgery. Most affected scalp is thin with fewer sweat glands, which makes the tissue vulnerable to damage. Sometimes, in such case as ACC, it is also associated with bone defect [1]. The patients also suffer from cosmetic problems. Treating the hairless scalp with simple excision is difficult because of the tissue tension. There are several approaches for reconstructing thin and scarlike scalp including local flap, free flap, and tissue expansion. Covering the defect with a local flap results creates another hairless area at the donor site. In addition, local flaps are not enough for extensive region and results in scar due to extra incision. Free flap such as anterolateral thigh free flap can provide

Correspondence: Jong Won Hong

Department of Plastic and Reconstructive Surgery, Institute for Human Tissue

Restoration, Yonsei University College of Medicine, 50-1 Yonsei-ro, Seodaemun-

gu, Seoul 03722, Korea

E-mail: hsaturn@hanmail.net

Received September 23, 2019 / Revised October 7, 2019 / Accepted October 10, 2019 excellent cosmesis and durable scalp coverage but it also causes donor site morbidity and hairless reconstruction [2]. In addition, there is a problem of skilled surgeon and adequate equipment for performing the microsurgery. For these reasons, former options are undesirable. There is need for improved reconstructive methods for hairless lesions.

Scalp resurfacing using a tissue expander can be an effective method. The expanded scalp tissue has sufficient thickness and uniform hair distribution with unchanged hair follicles [3]. Ideally, the donor tissue will have similar characteristics compared to the recipient tissue for therapeutic and cosmetic reasons. If the lesion is significantly wider than the donor site, it is difficult to resurface the lesion with one-stage tissue expansion. We report two cases of serial resurfacing of hairless scalp by re-expansion of a previously expanded scalp flap in one patient with ACC and another with dermatofibrosarcoma protuberans (DFSP).

\section{CASE REPORT}

\section{Case 1}

A 20-year-old woman visited the department of plastic and re- 
constructive surgery with a chief complaint of a congenital hairless patch on the vertex. The patient had no specific medical history and was within the normal range of social age, including intelligence. Physical examination revealed bilateral brachydactyly. The size of the hairless scalp was $23 \times 16 \mathrm{~cm}(368$ $\mathrm{cm}^{2}$ ), accounting for approximately $50 \%$ of the whole scalp. A skin-to-dura area was observed, without soft tissue and bone underneath the skin layer. This area showed pulsation from the brain under the scalp. Computed tomography revealed normal intracranial structures but no overlying skull bone.

A total of three operations were performed. The lesion extended from the frontoparietal area to the upper part of the occipital area. During tissue expander insertion, dissection was performed through the supragaleal plane beneath the site containing the hair. Tissue expanders were inserted in the parietal area bilaterally (left: $550 \mathrm{~mL} /$ rectangle and right: $250 \mathrm{~mL} / \mathrm{ellipti}$ cal; Mentor, Irving, TA, USA) (Fig. 1, A and B). Tissue expanders were fully expanded in the outpatient clinic before the second operation.

Despite the large-sized tissue expander, the expanded scalp flaps were not sufficient to resurface the entire hairless scalp area. Therefore, we planned to insert new expanders after excising part of the hairless area. After removing the previously inserted tissue expanders and excising a portion of the hairless scalp, there were $13 \times 10-\mathrm{cm}\left(130 \mathrm{~cm}^{2}\right)$ and $5 \times 8-\mathrm{cm}\left(40 \mathrm{~cm}^{2}\right)$ hairless lesions in the parietal and occipital areas, respectively. Additional tissue expanders were inserted in occipital area (150 $\mathrm{mL} /$ rectangle, Mentor) and frontal area $(25 \mathrm{~mL} / \mathrm{elliptical}$, Mentor) (Fig. 1, C and D).

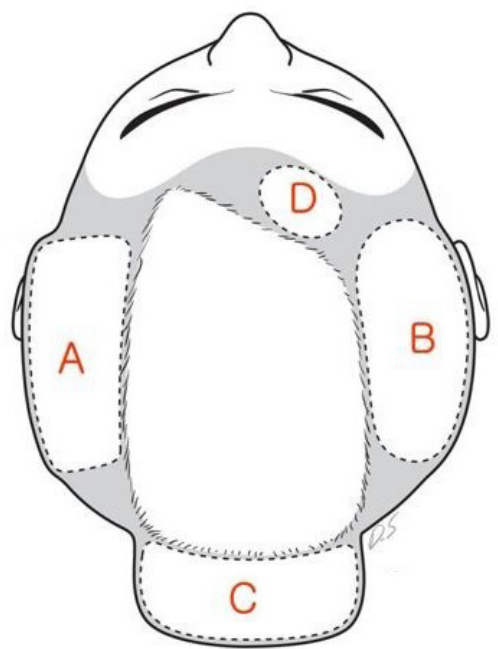

Fig. 1. First expander insertion in bilateral parietal areas (A, left: $550 \mathrm{~mL} /$ rectangle and B, right: $250 \mathrm{~mL}$ /elliptical; Mentor). After resurfacing using the first expanded flap, the frontal and occipital area were re-expanded $(\mathrm{C}$, occipital area: $150 \mathrm{~mL} /$ rectangle and $\mathrm{D}$, frontal area: $25 \mathrm{~mL} /$ elliptical; Mentor).
Serial expansions to re-expand the flap were performed. After full expansion, a final reconstructive operation using the expanded flap was performed. The expander was removed through the previous incision site. Finally, the re-expanded flap was advanced with a capsulectomy, and the defect was successfully resurfaced (Fig. 2). The hairless scalp was excised considering the size of expanded flap in each stage.

\section{Case 2}

A 42-year-old man had an $8 \times 3$-cm mass in the parieto-occipital area. The patient had no specific medical history. The tumor has grown gradually over the years. Pathological examination revealed a DFSP. A wide excision with a $3-\mathrm{cm}$ safety margin was performed. After tumor resection, the scalp defect was $16 \times 9 \mathrm{~cm}\left(144 \mathrm{~cm}^{2}\right)$, and a skin graft was initially used to cover the defect.

Tissue expander insertion was performed after 3 months of tumor resection. Two expanders were inserted (left: $250 \mathrm{~mL} /$ rectangle and right: $550 \mathrm{~mL} /$ rectangle; Mentor). Six months after insertion, they had been fully expanded. The tissue expanders were removed, and part of hairless scalp was removed and covered with the expanded flap. Because of the large size of the lesion from the initial surgery, a partial defect $(5 \times 6 \mathrm{~cm}, 30$ $\mathrm{cm}^{2}$ ) remained. A year later, serial expansion was planned for the previous expanded flap. The tissue expander was inserted in occipital area to the right to the hairless lesion $(100 \mathrm{~mL} / \mathrm{rect}-$ angle, Mentor). After 3 months, full expansion was achieved, and the second-stage serial tissue expander was removed along with the capsules. The hairless scalp was excised, and the re-expanded flap was sufficient to cover the defect (Fig. 3).

\section{DISCUSSION}

Surgical options for large hairless scalp lesions include the use of skin grafts, scalp flaps, and tissue expansion [4]. Skin grafts produce a hairless lesion as well as contour irregularity. With a local flap, the defect can be covered in a single procedure, but it is often inadequate. Free flaps are a good option for scalp reconstruction, but they are hairless. Resurfacing with tissue expansion can be a good choice for hair restoration. However, it is hard to treat large defects with one-stage tissue expansion because of the relatively lower elasticity of scalp skin.

The first patient visited the clinic with hairless scalp due to ACC during adulthood and had not previously been treated for the condition. The main purpose of treatment is to eliminate the hairless scalp and minimize the inconvenience it brings to daily life. Previously reported surgical treatment for ACC was for covering large scalp defects in children younger than 3 years 

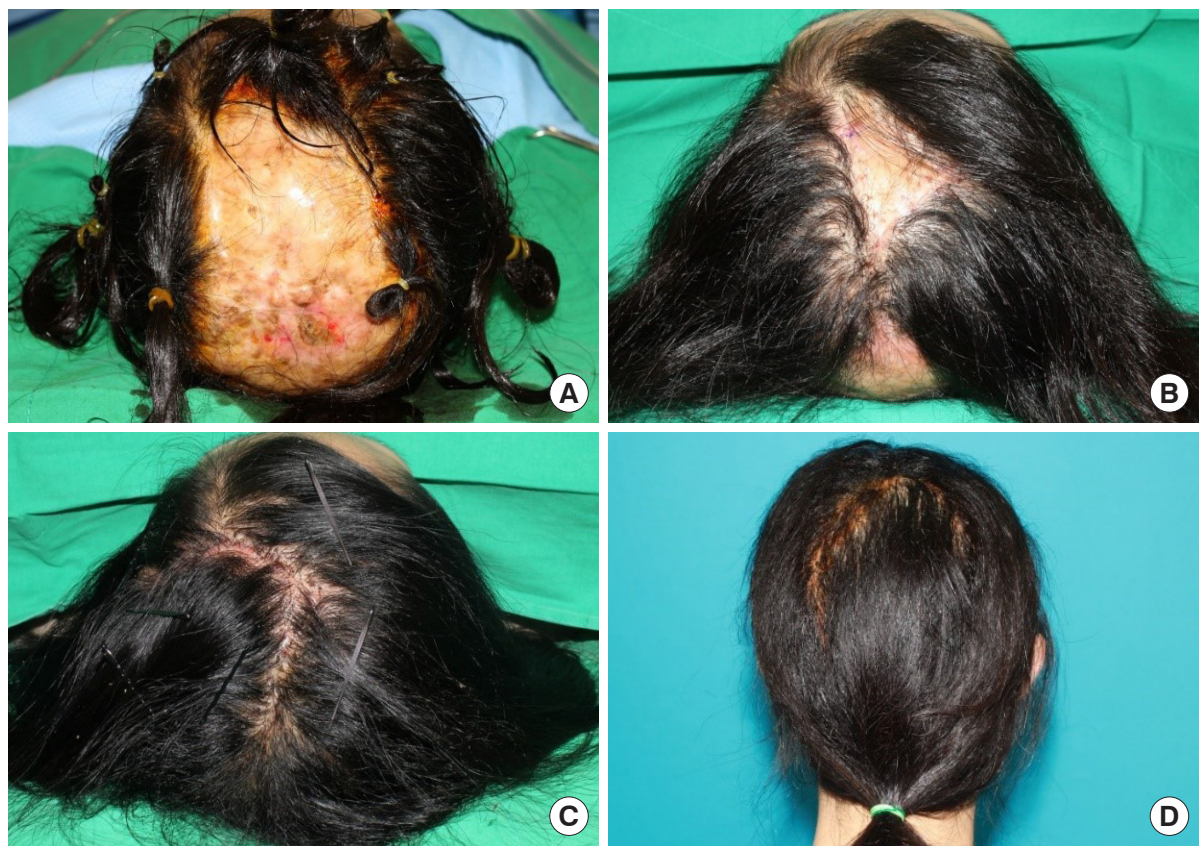

Fig. 2. A 20 -year-old woman patient (case 1). (A) Preoperative image (vertex view). The hairless scalp size was estimated as $23 \times 16 \mathrm{~cm}(368$ $\mathrm{cm}^{2}$ ) from the frontoparietal to upper occipital area. (B) Immediate postoperative image after bilateral parietal scalp expansion, partial removal of hairless scalp, and insertion of tissue expanders in the frontal and occipital areas (vertex view). There remained $13 \times 10-\mathrm{cm}\left(130 \mathrm{~cm}^{2}\right)$ and $5 \times 8-\mathrm{cm}\left(40 \mathrm{~cm}^{2}\right)$ hairless lesions in the parietal and occipital areas, respectively. (C) Immediate postoperative image after serial expansion of the frontal and occipital areas, complete removal of the hairless scalp, and coverage with expanded flaps (vertex view). (D) Follow-up image 15 months after operation shows good hair density and distribution (posterior view).
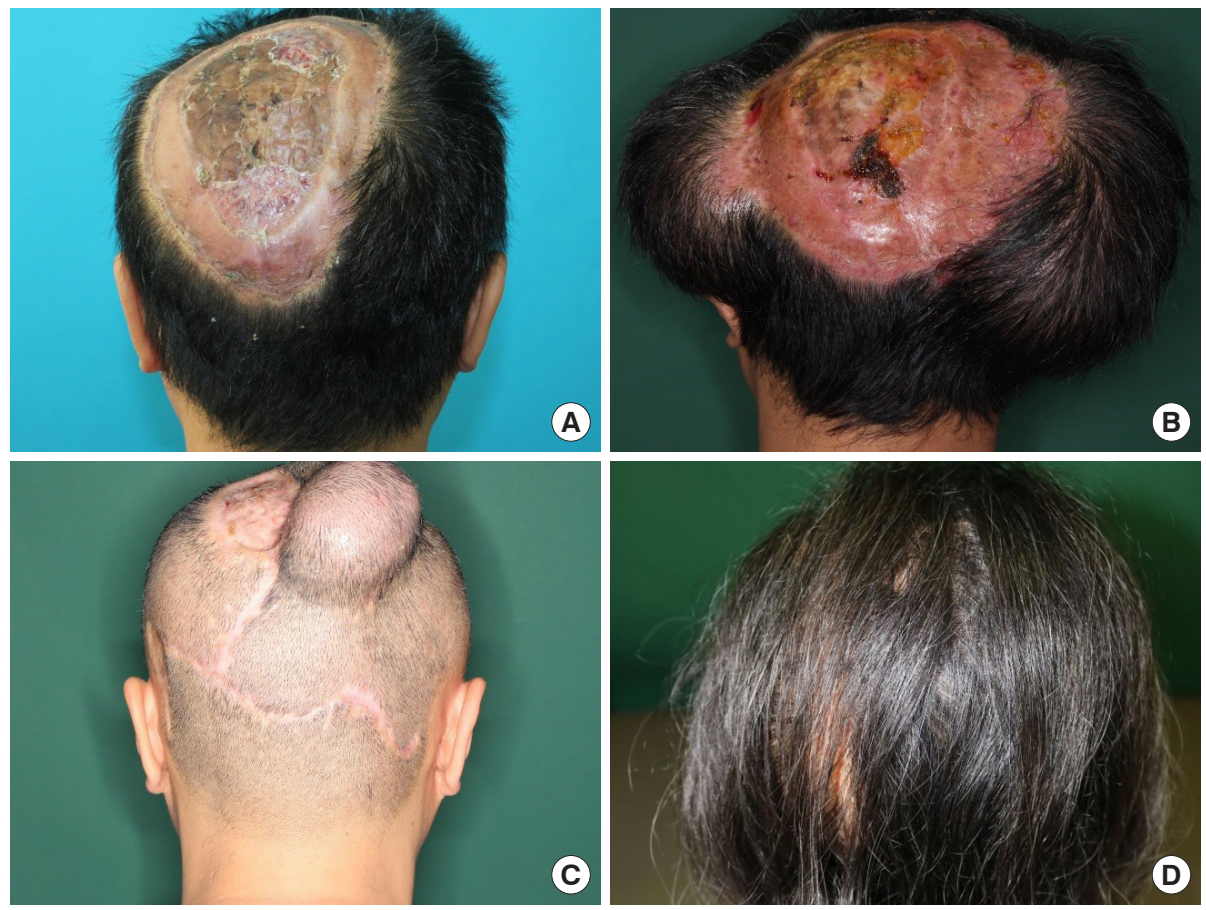

Fig. 3. A 42-year-old man patient (case 2). (A) Preoperative image (posterior view). There was a hairless scalp lesion sized $16 \times 9 \mathrm{~cm}\left(144 \mathrm{~cm}{ }^{2}\right)$ after dermatofibrosarcoma protuberance resection. (B) Image after full expansion of the first tissue expander (posterior view) (left: $250 \mathrm{~mL} /$ smooth rectangle and right: $550 \mathrm{~mL} / \mathrm{smooth}$ rectangle; Mentor). (C) Preoperative image before the final operation (posterior view). After removal of the first expander and resurfacing, a $5 \times 6 \mathrm{~cm}\left(30 \mathrm{~cm}^{2}\right)$ remained. The second expander was inserted into the previously expanded flap in the upper occipital area. Full expansion state $(100 \mathrm{~mL} /$ rectangle, Mentor). (D) Follow-up image showing successful scalp resurfacing 9 months after the final operation (posterior view). 
of age. In those cases, the goal of reconstruction was to eliminate the risk of life-threatening hemorrhage or infection, with a focus on functional restoration [5-7].

The second patient presented with a large defect $(16 \times 9 \mathrm{~cm}$, $144 \mathrm{~cm}^{2}$ ) due to DFSP resection. We initially considered a free flap from the anterolateral thigh to cover the defect but changed the plan to tissue expansion for hair restoration. To resurface the hairless scalp, we expanded the previously expanded scalp flap. The patient had a skull bone defect, but the skull at the site of expander insertion was normal, and the scalp thickness and hair condition were good.

The plane that contains the tissue expander can be divided into subgaleal and supragaleal components. Expander insertion in the subgaleal plane reduces the risk of bleeding and prevents skin thinning during the expansion process. On the other hand, the supragaleal plane can avoid the expansion of the rigid galea, so it can expand more rapidly and reduce patient discomfort accordingly [8].

In both cases, we chose the supragaleal plane, and capsulectomy was performed intraoperatively to cover the large defects. Despite supragaleal dissection, scalp flap vascularity was well preserved in both cases. To maintain tissue vascularity, re-expansion was only performed at the same site once. Even after re-expansion, hair density was well preserved cosmetically.

There is controversy regarding whether re-expansion should be performed immediately or delayed. Our experiences will help other surgeons select an approach to resurface large hairless scalp lesions using tissue expanders. We performed scalp resurfacing by serial tissue expansion to treat the hairless lesions in one patient with ACC and one with postoperative hairless scalp.

The limitations of these cases include long total treatment time with multiple operations over 2 years. In addition, the patients were adults with no further skull growth occurred. This method cannot be applied for pediatric patients. Despite the presence of a skin-to-dura area for case 1 , it is regrettable that neurosurgical operations such as cranioplasty with autologous bone or artificial material are actively used to solve the skull defect.

\section{NOTES}

\section{Conflict of interest}

No potential conflict of interest relevant to this article was reported.

\section{Ethical approval}

The study was approved by the Institutional Review Board of Severance Hospital (IRB No. 4-2019-0768) and performed in accordance with the principles of the Declaration of Helsinki.

\section{Patient consent}

The patients provided written informed consent for the publication and the use of their images.

\section{ORCID}

Dongwoo Shin https://orcid.org/0000-0002-6081-9646

Yong Hun Kim https://orcid.org/0000-0002-6092-4374

Han Gyeol Song https://orcid.org/0000-0002-8834-9279

Jong Won Hong https://orcid.org/0000-0002-7762-0940

\section{REFERENCES}

1. Blionas A, Giakoumettis D, Antoniades E, Drosos E, Mitsios A, Plakas S, et al. Aplasia cutis congenita: two case reports and discussion of the literature. Surg Neurol Int 2017;8:273.

2. Lamaris GA, Knackstedt R, Couto RA, Abedi N, Durand P, Gastman B. The anterolateral thigh flap as the flap of choice for scalp reconstruction. J Craniofac Surg 2017;28:472-6.

3. Pasyk KA, Austad ED, McClatchey KD, Cherry GW. Electron microscopic evaluation of guinea pig skin and soft tissues "expanded" with a self-inflating silicone implant. Plast Reconstr Surg 1982;70:37-45.

4. Smartt JM Jr, Kim EM, Tobias AM, Yan AC, Kirschner RE. Aplasia cutis congenita with calvarial defects: a simplified management strategy using acellular dermal matrix. Plast Reconstr Surg 2008;121:1224-9.

5. Schnabl SM, Horch RE, Ganslandt O, Schroth M, Dragu A, Bach $\mathrm{AD}$, et al. Aplasia cutis congenita: plastic reconstruction of three scalp and skull defects with two opposed scalp rotation flaps and split thickness skin grafting. Neuropediatrics 2009;40: 134-6.

6. O'Neill JK, Carter M, Warr RP. Aplasia cutis congenita: a case of scalp defect repair using two opposing bipedicled local flaps. J Plast Reconstr Aesthet Surg 2010;63:e242-4.

7. Raposo-Amaral CE, Raposo-Amaral CA. Aplasia cutis congenita: impact of early treatment on calvarial osteogenesis. J Plast Reconstr Aesthet Surg 2011;64:e237-40.

8. Prakash V, Tandon R, Mantri R. Supragaleal placement of tissue expander for post-burn alopecia. J Plast Reconstr Aesthet Surg 2006;59:1102-4. 